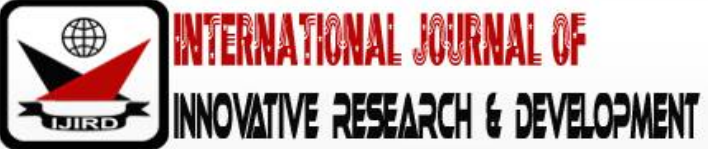

ISSN 2278 - 0211 (Online)

\section{Production of Thermal Insulating Material Using Scoria}

Okonkwo, Emmanuel Tochukwu
Principal Technology Officer, Department of Technology Transfer Registration
National Office for Technology Acquisition and Promotion (NOTAP) Abuja, Nigeria
Mudiare Edeki
Senior Lecturer, Department of Metallurgical and Materials Engineering,
Federal University of Technology, Minna, Niger State, Nigeria
Okonkwo, Chikezie Onyeka
Lecturer, Department of Mathematical Sciences,
Ajayi Crowther University, Oyo, Oyo State, Nigeria

\begin{abstract}
:
Insulation of the combustion chambers has continued to gain prominence over time because of the desire to improve the thermal efficiency of the systems. The present study investigated the suitability of scoria as an insulating material. Three different batches of scoria, clay and naphthalene were mixed. Scoria served as the matrix, clay served as the binder and naphthalene as the pore creator. The first batch contained $17.6 \%$ clay, the second contained 30\%, while the third batch contained $39.1 \%$. From each batch, test samples were prepared at varying percentage naphthalene content. Test samples were moulded into different shapes, depending on the test to be carried out on them. They were then allowed to dry under ambient air. This process was followed by oven-drying for 2 hours at $110^{\circ} \mathrm{C}$ to further reduce the moisture content of the test samples. The test samples from batch 1 disintegrated during the drying stage leaving only batches 2 and 3 . The test samples were thereafter fired in an electric kiln to a temperature of $1000^{\circ} \mathrm{C}$. Following the firing process, test samples from batches 2 and 3 were subjected to apparent porosity, bulk density, thermal shock resistance and thermal conductivity tests. At $40 \%$ naphthalene addition, the percentage apparent porosity values obtained for batch 2 and 3 test samples were $73.13 \%$ and $63.23 \%$. Bulk density values at the same naphthalene addition were 1.27 and $1.36 \mathrm{gcm}^{-3}$ respectively. Between $0 \%$ and $40 \%$ naphthalene addition, the thermal conductivity values for batches 2 and 3 test samples steadily reduced from $0.14-0.04$ $\mathrm{W} / \mathrm{m} . \mathrm{K}$ and $0.27-0.09 \mathrm{~W} / \mathrm{m} . \mathrm{K}$. The thermal shock resistance of the test samples from batches 2 and 3 also decreased from 12 to 7 and 13 to 6.5 cycles respectively. Test samples produced from batch 2 produced better results overall, which proved scoria to be suitable for use as a thermal insulating material.
\end{abstract}

Keywords: Scoria, naphthalene, clay, thermal conductivity, porosity, bulk density

\section{Introduction}

Thermal insulation materials have found very useful applications in different areas, including their use as lagging materials in stoves, incinerators, kilns, ovens, chimneys and furnaces. This is basically because of their effectiveness in minimizing heat energy losses (Canbolat et al, 2013). A typical example of a system which operates more efficiently as a result of the introduction of insulation is the wood burning cookstove. In this system, less fuel is consumed because the fire is hotter as a result of the insulation thus translating to reduced cost; pollution rate is greatly reduced because hot fire burns smoke; and cooking time is reasonably reduced (Bryden et al., 2005)

A lot of materials are being used for the purpose of thermal insulation but prominent among these are Insulating Refractories and other clay-based lagging materials. Insulating Refractories are particularly significant because as the name implies, they are refractories with low heat transfer i.e. being refractories, they withstand hear and being insulating, prevent heat transfer. The ability of refractories to withstand very high temperature makes them indispensable thermal insulators, particularly in the production of metals and metal objects (Searle, 1948). Refractories are classified as either clay based or non-clay based. Satyendra (2013) however noted that clay-based refractories which are "essentially hydrated aluminium silicates with minor proportion of other minerals" are the most common form of refractory material hence its extensive use as lagging material in furnaces, kilns,stoves, and ovens (Ayugi, 2011).

Some naturally occurring insulating materials such as vermiculite, perlite and pumice have also been used in the production of insulating bricks. In this process, the materials are combined in a pre-determined proportion with a combustible material which may be organic or inorganic, while a binding material such as clay is used to hold the 
lightweight material in place. The combustibles either evaporate or burnout during the initial stage of firing, resulting in the formation of pores within the material (Kumar, 2011).

In the concept of thermal insulation, it is important to remember that heat would normally flow by convection, conduction and radiation. However, for motionless air, heat transfer by convection and conduction are negligible thus, only radiative heat is markedly transferred. Therefore, in order to limit the amount of heat flow by conduction and convection, air is contained in porous materials which are to serve as insulators (Cornwell, 1977). Insulating Refractories are therefore characterised by the amount and nature of pores contained in them. The more the isolated pores in the material, the less the amount of heat that is transmitted across the body. Thus, porosity of a thermal insulator is known to be inversely proportional to its thermal conductivity and its bulk density.

Magma (Molten rock), deep in the earth's crust and under high pressure contains dissolved gasses and steam. Upon eruption, the molten rock solidifies quickly without allowing enough time for the dissolved gasses to escape. Hence, they are trapped in the rock as minute pores. Scoria and Pumice are igneous rocks which are formed through this process. While Pumice is very similar to scoria, there are some notable differences between both materials. These are as follows:

\begin{tabular}{|c|c|c|}
\hline & Pumice & Scoria \\
\hline Colour & White or light grey & Dark grey or reddish brown \\
\hline Composition & Felsic (Rhyolitic) volcanic rock & Mafic (Basalt or Andesite) \\
\hline Density & Lightweight (can float on water) & Lightweight but cannot float \\
\hline Texture & $\begin{array}{c}\text { Contain abundant small cavities (so } \\
\text { many that the walls between them } \\
\text { are very thin hence their very low } \\
\text { density) }\end{array}$ & $\begin{array}{c}\text { Abundant large vesicles (Mafic magmas are } \\
\text { less viscous than felsic magmas which is why } \\
\text { gas bubbles in scoria can move more freely } \\
\text { and join each other to form larger vesicles) }\end{array}$ \\
\hline \multicolumn{2}{|c|}{$\begin{array}{c}\text { Table 1: Differences between Pumice and Scoria } \\
\text { Source: Geology.Com }\end{array}$}
\end{tabular}

According to Taha and Mohamed (2013), Scoria is readily available in different locations around the world where volcanic activities have taken place and Nigeria happens to be one of such places. Lar et al., (2013) has confirmed the existence of large volcanic provinces around Jos, Plateau State in Central Nigeria and Biu in Borno State which occupy the eastern half of Nigeria and situated parallel to the Cameroonian volcanic line. Scoria has been confirmed to be more abundant in Nigeria than Pumice. The application of Scoria as a thermal insulating material therefore, was primarily based on its availability in addition to the exploitation of its naturally existing pores and low density.

\section{Materials and Methods}

The experiments were performed at the Ceramics Laboratory of the Project Development Institute, (PRODA) Enugu. The materials used for this study are Scoria, Clay and Naphthalene. The equipment used for this study include; a jaw crusher, ball mill, POP bath, set of sieves, a furnace, weighing balance, dryer and thermal conductivity meter. Scoria samples obtained from the base of a volcanic cone located in Miango village in Bassa Local Government Area (LGA) of Plateau State, Nigeria were crushed and passed through a stack of sieves. Scoria sample with particle sizes of $4.75 \mathrm{~mm}$ and less were retained. The unprocessed clay which was obtained from Ukpo in Anambra State, Nigeria was soaked for two days in water and allowed to deflocculate and settle. The suspended foreign particles were then decanted after which more water was added to the clay to form slurry. The mixture was allowed to stand still for another three days. A floating clear liquid which formed on the clay was decanted and the processed sample was poured into a Plaster of Paris (P.O.P) bath and left for three days so as to allow for complete drainage of the liquid present in the processed clay sample. This was followed by a drying process in an isotherm oven for two hours at $110^{\circ} \mathrm{C}$ after which the dried clay cake samples were ground in a ball mill. Sieving of the clay sample was then carried out to obtain particle sizes of $2.36 \mathrm{~mm}$ and less. In respect of the Naphthalene used for this study, Naphthalene balls were crushed using a ceramic mortar and pestle; it was then sieved to obtain samples with particle sizes of $2.36 \mathrm{~mm}$. Two batches of the mixture of scoria and clay were prepared. In the first batch, each sample of $1 \mathrm{~kg}$ contained $30 \%$ clay while each sample of the scoria/ clay mixture of batch 2 contained $39.1 \%$ clay. Both batch samples were prepared with the following proportions of naphthalene: $100 \mathrm{~g}, 200 \mathrm{~g}, 300 \mathrm{~g}$ and $400 \mathrm{~g}$. Each of the batches was thoroughly mixed with a little water to induce plasticity and homogeneity and then pressed into moulds to produce test pieces of different shapes and dimensions by simple compaction method depending on what tests they were to be used to conduct. The test pieces produced are as follows:

- 7.5 × 4.0 × $1.5 \mathrm{~cm}$ (cuboid shape): Test pieces produced to this dimension were used as test samples for the Apparent Porosity and Bulk Density tests.

- $\quad 12.7 \mathrm{~cm} \times 12.7 \mathrm{~cm} \times 0.95 \mathrm{~cm}$ (cuboid shape): Test pieces produced to this dimension were used as test samples for the Thermal Conductivity tests.

- $\varnothing 3 \times 2 \mathrm{~cm}$ (Cylindrical shape): Test pieces produced to this dimension were used as test samples for the Thermal Shock tests.

The resulting samples were dried in an oven to remove moisture after which they were fired in a furnace at $1000^{\circ} \mathrm{C}$. Tests performed on the fired samples were apparent porosity, bulk density, thermal conductivity and thermal shock tests. 


\subsection{Apparent Porosity}

The fired test samples were exposed in ambient air for 12 hours. The dry weight of each of the test sample (D) was measured. Each of the samples was then immersed in water and soaked for 6 hours after which each sample was weighed while being suspended in air. The resulting weight was recorded as saturated weight (W). Finally, the test samples were weighed again when immersed in water and the results were recorded as suspended weight (S). The apparent porosity was then calculated using the expression:

$$
\mathrm{P}=\frac{\mathrm{W}-\mathrm{D}}{\mathrm{W}-\mathrm{S}} \times 100 \%
$$

$\mathrm{D}=$ Weight of dried specimen, $\mathrm{S}=$ weight of specimen soaked in water and suspended in water, and $\mathrm{W}=$ Weight of specimen soaked in water and suspended in air. (Berger, 2010)

\subsection{Bulk Density}

The parameters obtained during the apparent porosity experiment were applied to the following equation to obtain the bulk density of the material

$$
\text { Bulk Density }=\frac{\mathrm{D}}{(\mathrm{W}-\mathrm{S})}\left(\frac{\mathrm{g}}{\mathrm{cm}^{3}}\right)
$$

2.3. Thermal Conductivity (Using a Pasco Scientific Thermal Conductivity Apparatus, Model TD-8561).

Test samples used in the experiment were produced in the specified dimension of $12.7 \mathrm{~cm}^{2}$ and thickness of $0.95 \mathrm{~cm}$.

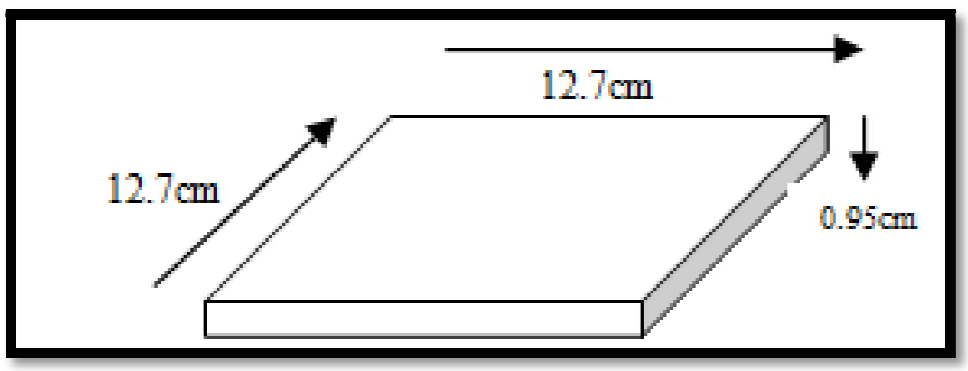

Figure 1

Each sample was clamped between the steam chamber of the apparatus, which was maintained at a constant temperature of $100^{\circ} \mathrm{C}$ and a block of ice which was maintained at a constant temperature of $0^{\circ} \mathrm{C}$, thereby creating a temperature differential of $100^{\circ} \mathrm{C}$ between the top and the bottom surfaces of the test sample. The diameter of the ice used to generate a temperature differential was recorded. Melted ice was collected from the sprout of the apparatus and ambient melting rate of the ice obtained by determining the mass of the container without melted ice, collecting the melted ice over a specific time period, determining the mass of container plus melted ice and subtracting the first mass from the second. Steam was then fed into the steam chamber for several minutes and the earlier steps taken in obtaining ambient meting rate was repeated. New diameter of the ice after melting was recorded and the average diameter noted. This was then used to calculate the area over which the heat flow between the ice and the steam chamber took place. The rates at which the ice melted before and after the steam was turned on was obtained by dividing mass of melted ice by time when there was no steam in the steam chamber and mass by time when there was steam in the steam chamber respectively. Finally, the rate of melting due to temperature differential was obtained by subtracting the rate of melting before steam was turned on from the rate after steam was turned on. The thermal conductivity, $\mathrm{K}$ for each test sample was then determined using the following Equation

$\mathrm{K}=\frac{\Delta \mathrm{Q} \mathrm{h}}{\mathrm{A} \Delta \mathrm{T} \Delta \mathrm{t}}=\frac{(\text { mass of melted ice })(80 \mathrm{cal} / \mathrm{gm})(\text { thickness of material })}{(\text { area of ice })(\text { time during which ice melted })(\text { temperature differetial })}=\frac{\mathrm{Cal} \mathrm{cm}}{\mathrm{cm}^{2} \operatorname{sec~}_{\mathrm{K}}}$

The data obtained using the equation above was multiplied by the conversion factor, 418 to obtain the thermal conductivity values in $\mathrm{W} \mathrm{m}^{-1} \cdot \mathrm{K}^{-1}$

Equation (3) above is a variant of the Fourier's equation which is given as

${ }_{\Delta} \mathrm{Q}=\mathrm{K} \cdot \mathrm{A}\left(\frac{\mathrm{dT}}{\mathrm{dx}}\right) \cdot \Delta \mathrm{t}$

Where ${ }_{\Delta} \mathrm{Q}=$ amount of heat; $\mathrm{K}=$ thermal conductivity; $\frac{\mathrm{dT}}{\mathrm{dx}}=$ temperature gradient through the conducting medium and $\Delta \mathrm{t}=$ change in time 


\subsection{Thermal Shock Test}

The test samples used in the experiment were produced to $\varnothing 3 \times 2 \mathrm{~cm}$ dimension.

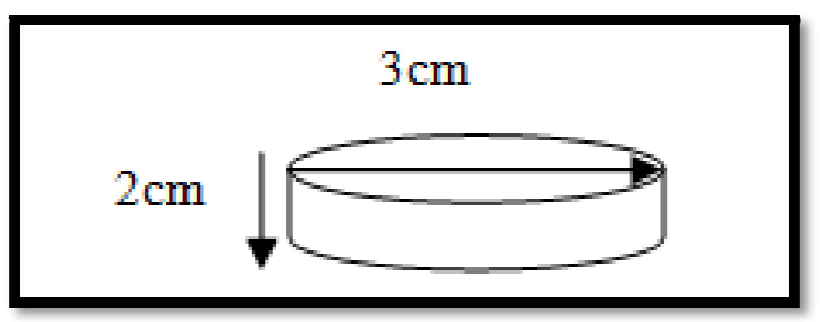

Figure 2

Each of the test samples produced from the mixture of scoria, clay and naphthalene was carefully placed in the electrically heated furnace and fired to a temperature of $1000{ }^{\circ} \mathrm{C}$. The furnace was then held at this temperature for 2 hours after which the test samples were withdrawn using a tong and placed on a ceramic slab for 10 minutes at ambient temperature. The process was repeated until a crack visibly appeared on the surface of each test piece. Upon observation of the crack, the cracked test sample was withdrawn from the process. The number of cycles that each test piece withstood before the observation of the crack was recorded and taken to be a measure of its thermal shock resistance.

\section{Results and Discussion}

Tables 1 and 2 respectively show the different mixtures of samples at different percentage naphthalene addition for the two batches (1 and 2) used in the study. The table clearly shows that the test samples were prepared by replacing $0 \%, 10 \%, 20 \%, 30 \%$ and $40 \%$ of the scoria/ clay mix with naphthalene. In respect of the analysis conducted on the test pieces, the result as represented in figure 3 shows that apparent porosity increases with increase in percentage naphthalene. Samples with 30\% clay content recorded higher apparent porosity values than those with $39.1 \%$ clay content; increasing from $50.87 \%$ to $73.13 \%$ as against $41.84 \%$ to $63.23 \%$ recorded for the samples containing $39.1 \%$ clay. This result is attributable to the percentage constituent of scoria in each batch of test samples. The batch with $30 \%$ clay had a higher amount of scoria, hence more natural pores. Also, at similar percentage naphthalene, the Batch 1 samples with $30 \%$ clay had higher ratio of naphthalene to clay. After the naphthalene vaporized, more artificial pores were created compared to that of Batch 2 with 39.1\% clay (Bryden et al, 2005).

\begin{tabular}{|c|c|c|c|c|}
\hline $\begin{array}{c}\text { Sample } \\
\text { No. }\end{array}$ & $\begin{array}{c}\text { Weight of } \\
\text { Scoria (g) }\end{array}$ & $\begin{array}{c}\text { Weight of } \\
\text { Clay (g) }\end{array}$ & $\begin{array}{c}\text { Weight of } \\
\text { Naphthalene (g) }\end{array}$ & \% Naphthalene \\
\hline 1. & 700 & 300 & 0 & 0 \\
\hline 2. & 630 & 270 & 100 & 10 \\
\hline 3. & 560 & 240 & 200 & 20 \\
\hline 4. & 490 & 210 & 300 & 30 \\
\hline 5. & 420 & 180 & 400 & 40 \\
\hline
\end{tabular}

Table 2: (Batch 1 -Mix Ratios of Scoria and Naphthalene, bound with 30\% clay)

\begin{tabular}{|c|c|c|c|c|}
\hline $\begin{array}{c}\text { Sample } \\
\text { No. }\end{array}$ & $\begin{array}{c}\text { Weight of } \\
\text { Scoria (g) }\end{array}$ & $\begin{array}{c}\text { Weight of } \\
\text { Clay (g) }\end{array}$ & $\begin{array}{c}\text { Weight of } \\
\text { Naphthalene (g) }\end{array}$ & \% Naphthalene \\
\hline 1. & 609 & 391 & 0 & 0 \\
\hline 2. & 548.1 & 351.9 & 100 & 10 \\
\hline 3. & 487.2 & 312.8 & 200 & 20 \\
\hline 4. & 426.3 & 273.7 & 300 & 30 \\
\hline 5. & 365.4 & 234.6 & 400 & 40 \\
\hline
\end{tabular}

Table 3: (Batch 2 - Mix Ratios of Scoria and Naphthalene, Bound with 39.1\% Clay) 


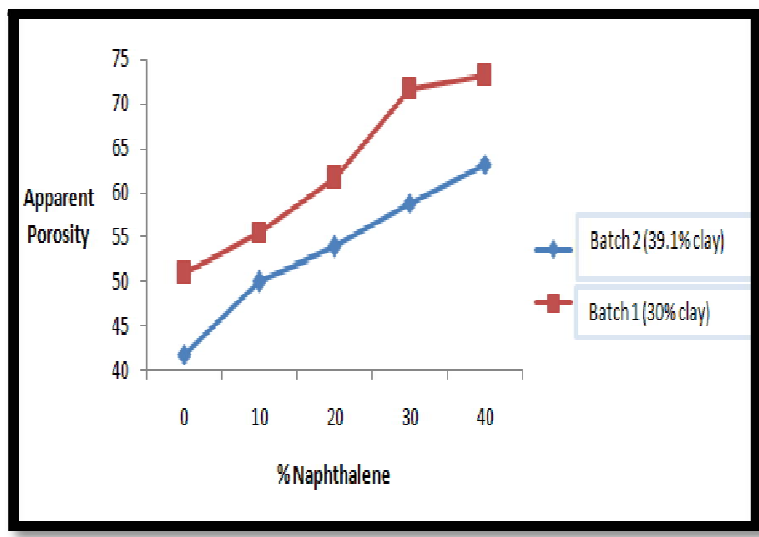

Figure 3: Apparent Porosity against Percentage Naphthalene for Batches 2 And 3

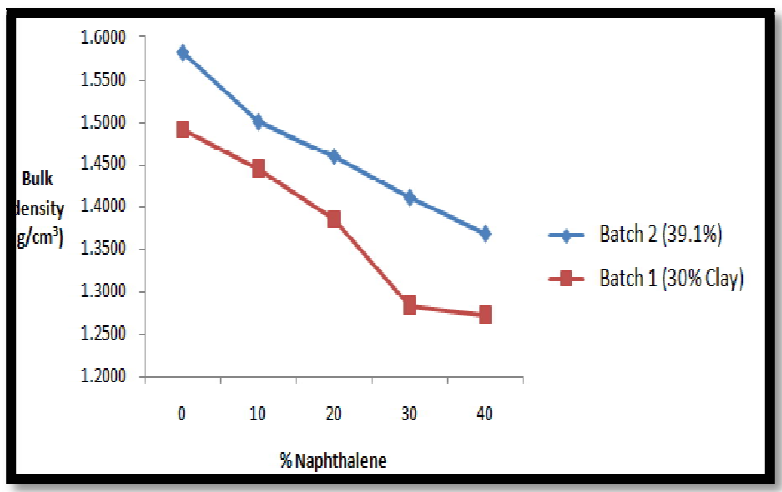

Figure 4: Bulk Density against Percentage Naphthalene for Batches 1 And 2

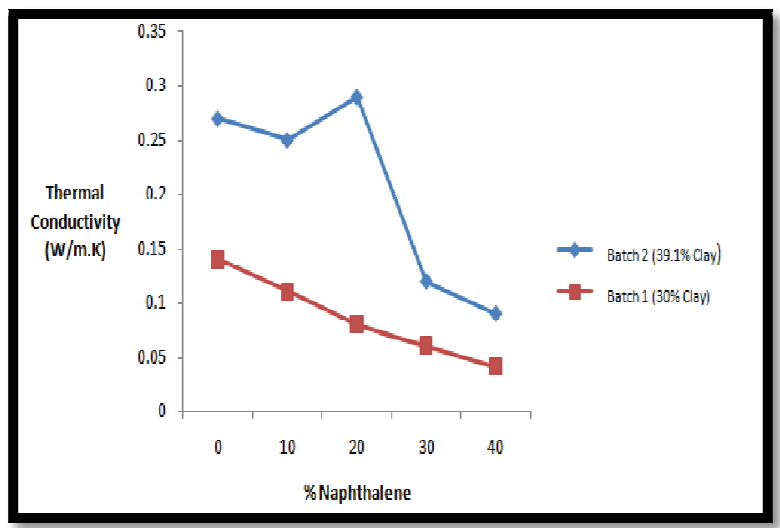

Figure 5: Thermal conductivity against percentage Naphthalene for batches 1 and 2

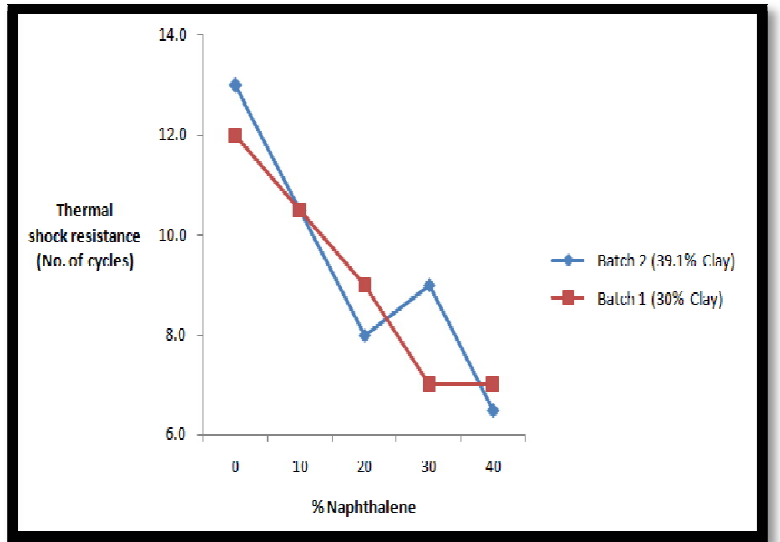

Figure 6: Thermal Shock Resistance against Percentage Naphthalene for Batches 1 And 2 
On the other hand, results of the bulk density test as represented in Figure 4 shows that the bulk density of the test samples reduced slightly as percentage naphthalene content increased. Samples with $39.1 \%$ clay content recorded

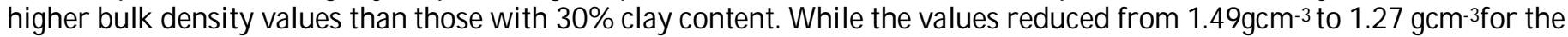
batch containing $30 \%$ clay, they reduced from $1.58 \mathrm{gcm}^{-3}$ to $1.36 \mathrm{gcm}^{-3}$ for the samples contacting $39.1 \%$ clay. The clay used in this study was reduced to very fine particle sizes unlike the Scoria particles which were not. The coarse nature of the Scoria samples used was due to the desire to retain the original pores contained in the material. Therefore, the mass of clay that occupied each unit volume of the test pieces was naturally higher in the samples that contained $39.1 \%$ clay even though the difference was marginal. The gradual decline in the bulk density of the materials with increase in the percentage of naphthalene is a direct consequence of the burning off of the naphthalene which resulted in the increase in the amount of pores created and a reduction in the matter content of the samples. The results obtained from the samples are close to the acceptable range of values for the bulk density of some common combustion chamber materials i.e. (0.16$0.04) \mathrm{g} / \mathrm{cm}^{3}$ (Schreiner, 2011).

In respect of the results obtained from the thermal conductivity tests carried out, Figure 5 shows that thermal conductivity values obtained from Batch 1 test samples with $30 \%$ clay content decreased steadily from $0.14-0.04 \mathrm{~W} / \mathrm{m} . \mathrm{K}$ with increase in percentage of naphthalene content. For Batch 2 test samples with $39.1 \%$ clay content, a decline in thermal conductivity value $0.27-0.09 \mathrm{~W} / \mathrm{m} . \mathrm{K}$ was also observed as percentage of naphthalene content increased. The high porosity of the resulting material plays a vital role in the effective resistance to thermal energy flow across the material since still air possesses one of the lowest thermal conductivity values of $0.024 \mathrm{~W} \mathrm{~m}^{-1} \mathrm{~K}^{-1}$ (Cornwell, 1977). Furthermore, the results obtained from samples of both batches, particularly the sample from batch 1 fall within the acceptable thermal conductivity values range of $0.038-0.142 \mathrm{~W} \mathrm{~m}^{-1} \mathrm{~K}^{-1}$ for some common combustion chamber materials (Schreiner 2011).

From Figure 6, it is observed that Batch 1 test samples with 30\% clay content recorded a steady decline in thermal shock resistance value from 12.0 - 7.0 cycles, with increase in percentage of naphthalene content. Batch 2 test samples with $39.1 \%$ clay content, also recorded a decline in thermal shock resistance value from 13.0 - 6.5 cycles as percentage naphthalene content increased. The decrease in thermal shock resistance of the samples with increase naphthalene content could be attributed to the increased amount of open pores in the sample which may act as a stress concentrator from where cracks may be propagated (Aramide, 2012). In addition, a plausible explanation as to why the samples from Batch 2 failed faster than those from Batch 1 could be that as the amount of pores in the sample increased in direct proportion with the percentage of naphthalene, the mixture with more clay thus became more susceptible to thermal shock because of the very brittle nature of fired clay at elevated temperatures.

\section{Conclusion}

From the tests conducted and the results obtained, it can be concluded that;

- The natural pores contained in the scoria rock had a positive impact on the porosity of the final material and consequently, on the thermal conductivity and bulk density of the material

- Low bulk density values obtained would result in lower thermal mass during application, which would translate to lower stored energy and less fuel consumption

- The superior behaviour of batch 1 test samples in comparison with batch 2 samples is due to the higher scoria content in the former which contained more natural pores than the latter

- Thermal shock resistance of scoria is higher than that of fired clay. This is deducible from the fact that batch 2 samples which contained higher amount of clay had would translate to higher amount of pores with increase in naphthalene content and thus reduce thermal shock resistance

- Scoria, naphthalene and clay samples containing $30 \%$ of clay possesses more acceptable properties and hence would serve as a better thermal insulator.

\section{References}

i. Aramide F.O (2012). Production and Characterization of Porous Insulating Fired Bricks from Ifon Clay with Varied Sawdust Admixture. Journal of Minerals and Materials Characterization and Engineering, 2012, 11, 970 975

ii. Ayugi, G. (2011). Thermal Properties of Selected Materials for Thermal Insulation Available in Uganda. A Dissertation submitted to the Directorate of Research and Graduate Training. Makarere University, Uganda

iii. Berger, M.B. (2010). The Importance and Testing of Density / Porosity / Permeability / Pore Size for Refractories. The Southern African Institute of Mining and Metallurgy Refractories 2010 Conference pp 101-116

iv. Bryden, M., Still, D., Scott, P., Hofa, G., Ogle, D., Balis, R. \& Goyer, K. (2005). Design Principles for Wood Burning Cook Stoves: Aprovecho publication, Aprovecho Research Centre, Oregon, USA.

v. Canbolat, S., Kut, D., Dayioglu, H. \& Merdan, N. (2013). Investigation of the Effects of Pumice Stone Powder and Polyacrylic Ester based Material on Thermal Insulation of Polypropylene Fabrics. Tekstil ve Konfeksiyon - Journal of Textile and Apparel, 23(4), 349-356.

vi. Cornwell, K (1977). The Flow of Heat. Van Nostrand Reinhold Company Limited, Berkshire, England Chapter 2, pp $39-41$

vii. Kumar, R. (2011). Development of Low Bulk Density Fireclay Insulation Bricks. A thesis submitted in partial fulfilment of the requirement for the Degree of Bachelor of Technology in Ceramic Engineering. National Institute of Technology, Rourkela- 769008, India

viii. Lar, U.A., Lekmang, I.C., Shuaibu, M.T., Mahmud, U.M., \& Yakubu, T.A. (2013). Volcanoes of Nigeria: A Preliminary Study. 7th Conference on African Geology Assiut Egypt. 
ix. Pasco Scientific (1987). Thermal Conductivity Apparatus. Instruction Manual and Experiment Guide for the PASCO Scientific Model TD-8561.10101 Foothhills Blvd, Roseville, CA 95747-7100

x. Satyendra, (2013). Introduction to Refractories. Ispatguru.com. Retrieved from http:/ / ispatguru.com/ introduction-to-refractories/ on April 4, 2016, 6.19pm

xi. Schreiner, N.H. (2011). Performance Characteristics and Design Recommendations for Biomass-Burning Stoves Using Earthen Construction Materials. M.Sc Thesis: Environmental Engineering, Michigan Technological University, USA. Retrieved from

xii. Searle A.B. (1948). Tribute to Refractory Materials. Refractories for Furnaces, Kilns, Retorts e.t.c Crosby Lockwood and Sons Limited, London U.K

xiii. Taha, A.A. \& Mohammed, A.A. (2013). Chemical, Physical and Geotechnical Properties Comparison between Scoria and Pumice Deposits in Dhamar- Rada Volcanic Field South West Yemen. Australian Journal of Basic and Applied Sciences, 7 (11), 116-124. 